\title{
COMPARISON BETWEEN THREE-POINT AND FOUR-POINT FLEXURAL TESTS TO DETERMINE WOOD STRENGTH OF Eucalyptus SPECIMENS
}

\author{
Paulo Ricardo Gherardi Hein ${ }^{1, \diamond}$, Lö̈c Brancheriau ${ }^{2}$
}

In memoriam of Dr. Thomas C. MANNES

\begin{abstract}
Comparison between flexural wood strength values obtained from three-point and four-point bending tests in wood were only reported in few previous works, but remains unclear. Thus, the aim of this study was to determine the relationship between wood strength (MOR) obtained by 4-point and 3-point bending tests in Eucalyptus. Two or three specimens were cut from the same scantling (thus considered as twin) and submitted to flexural vibration tests. Then 190 wood specimens were tested by 4-point bending tests and 138 twin specimens were submitted to 3-point bending tests. Wood strength determined from 3-point bending test presented significantly higher mean value $(76,8 \mathrm{MPa})$ than that from 4-point bending test $(73 \mathrm{MPa})$. A linear regression for converting MOR from 3-point to 4-point bending test was proposed for these Eucalyptus specimens: $\mathrm{MOR}_{4 \mathrm{p}}=0,889$ $\times \mathrm{MOR}_{3 p}+5,14$ in $\mathrm{MPa}\left(\mathrm{R}^{2}=0,74\right)$. The correlation of MOR in 3-point bending with density was higher $\left(\mathrm{R}^{2}=0,57\right)$ than in 4 -point bending $\left(\mathrm{R}^{2}=0,45\right)$. The correlations between dynamic elastic moduli and moduli of rupture were similar ( circa $\mathrm{R}^{2}=0,57$ for $\mathrm{MOR}_{3 \mathrm{p}}$ and $\mathrm{R}^{2}=0,65$ for $\mathrm{MOR}_{4 \mathrm{p}}$ ).
\end{abstract}

Keywords: Acoustic vibration, density, Eucalyptus grandis, static bending test, stiffness, strength.

\section{INTRODUCTION}

Mechanical properties of the materials can be obtained from destructive and non destructive testing. Non-destructive tests are mostly based on propagation speed using acoustic or ultrasonic waves and acoustic spectral analysis in which dynamic elastic properties can be estimated.

Destructive tests are based on the application of a force on the specimen until it fails: the stress to strain plot, the maximum force until failure and the distance displaced are recorded (Kollmann and Côté 1968). According to Mujika (2006) mechanical properties, such as strength and stiffness, can be calculated using a range of test methods. In most cases 3-point bend and 4-point bend are suggested for prediction of flexural properties of the materials (Kumar and Murthy 2012). These bending tests simulate tensile and compression stress on a wood specimen and its physical response behavior is monitored. According to Chitchumnong et al. (1989) the fundamental differences are the location of the maximum bending moment and maximum axial fiber stresses: the maximum stress occurs directly below the loading nose in three-point loading, but is spread out over the area between the loading noses in the four-point system.

There are several standard procedures for performing bending tests in order to obtain flexural strength and flexural modulus. However, Brancheriau et al. (2002b) advises that the values obtained by one method cannot be directly compared with those of other methods and so the bending properties have to be converted before using them and correctly compared with others from different references. Therefore, they have proposed a formula for converting the modulus of elasticity of wood obtained from 3-point $\left(\mathrm{E}_{3 \mathrm{P}}\right)$ to a 4-point bend-testing modulus $\left(\mathrm{E}_{4 \mathrm{P}}\right)$ taking into account the shear force

${ }^{1}$ Departamento de Ciências Florestais - Universidade Federal de Lavras, Lavras, Brasil.

${ }^{2}$ CIRAD, Univ Montpellier, UR BioWooEB, Montpellier, France.

•Corresponding author: paulo.hein@dcf.ufla.br

Received: 21.09.2016 Accepted: 24.01.2018 
influence and supports and loading head indentation effect. The 3-point bending test systematically underestimates the modulus of elasticity. This phenomenon is due to the fact that the shear effect and the indentation effect of the loading head and the supports are neglected. The measured deflection in 3-point bending is the result of axial strains, longitudinal shear and indentation. The influence of shear stresses depends on the value of the length to height ratio. The influence of indentation depends on the wood stiffness, the load level applied and the shape of the loading head and supports.

Several studies have investigated this issue in a range of materials. For instance, Chitchumnong et al. (1989) have compared mechanical properties of dental polymers using three- and four-point bend-testing. They reported that the values for flexural strength from the three-point bend test were always higher, suggesting that that parameter is dependent on the testing procedure. Hayat and Suliman (1998) have evaluated the mechanical properties of glass reinforced phenolic laminates using three-point bending and four-point bending tests. Flexural modulus and failure stress obtained by three-point were higher than those obtained in four-point bending tests for most of treatments. In regard to wood, few studies have been done.

Sales (1977) has compared longitudinal modulus of elasticity obtained in 3-point and 4-point bending tests using three wood species: Nauclea diderrichii (Bilinga), Copaifera letestui (Gheombi) and Entandrophragma cylindricum (Sapelli). His experimental results show that $\mathrm{E}_{4 \mathrm{p}}$ is always higher than $\mathrm{E}_{3 \mathrm{p}}$. Bilinga wood specimens present $\mathrm{E}_{4 \mathrm{p}}$ of $17,024 \mathrm{MPa}$, a mean value $\sim 36 \%$ higher than the $\mathrm{E}_{3 \mathrm{p}}(12,543$ $\mathrm{MPa}$ ). The $\mathrm{E}_{4 \mathrm{p}}$ of Gheombi and Sapelli were, respectively $53,4 \%$ and $56,4 \%$ higher than $\mathrm{E}_{3 \mathrm{p}}$ mean values.

Riyanto and Gupta (1998) have evaluated the shear strength in Douglas-fir by several methods, including three-point bending, four-point bending, five-point bending and torsion. They reported that the mean shear strength value obtained from the three-point bending test method $(9,07 \mathrm{MPa})$ was $41 \%$ higher than the shear strength from the four-point bending test $(6,44 \mathrm{MPa})$. In a more complex study, Brancheriau et al. (2002b) compared these two test methods proposing a crossing analytic formula from a 3-point bending modulus of elasticity to a 4-point bending one using experimental data. They showed a 3 point bending test under-estimates the modulus of elasticity value by about $19 \%$ in relation to a 4 point loading. The under-estimations, which lead to a 3 point bending test when the shear effect and the indentation effect are neglected, are valued respectively at $8 \%$ and $11 \%$.

Results between flexural wood strength values obtained from three-point and four-point bending tests in wood were reported in few previous works (Gustafsson 2001, Yoshihara et al. 2003, Naylor et al. 2012), but the comparison between these static tests still remains unclear. Considering that many databases present wood mechanical properties obtained via several methods, it is necessary to know the link between flexural wood strength values obtained from the two main methods. Thus, the aim of this study was to investigate the relationship between wood strength (MOR) obtained by 4- and 3-point bending tests in Eucalyptus. In addition, wood density, elastic modulus from dynamic tests were compared to resistance obtained from static tests for verifying whether the acoustic method, which is faster than classical tests, is able to provide information concerning resistance properties of the materials.

\section{MATERIAL AND METHODS}

\section{Wood samples preparation}

Eucalyptus grandis $\times$ E. urophylla hybrids, 6 years old, grown $\left(19^{\circ} 17^{\prime} \mathrm{S}, 42^{\circ} 23^{\prime} \mathrm{W}\right.$, and altitude $230-500 \mathrm{~m}$ ) for pulp production in Brazil were used in this study. Young trees were selected for this study because the woods from fast-growing forests have been used more and more for temporary structures, construction or furniture. The high amount of juvenile wood could also increase the variability of the measured properties (MOR, dynamic moduli and density). Central boards (quarter sawn; length: two meters) taken from 40 trees were cut in order to generate 103 scantlings. The scantlings were air-dried under protected conditions during 90 days. Then, 328 specimens of $410 \mathrm{~mm}$ long (wood longitudinal direction) x $25 \mathrm{~mm}$ thick (radial direction) x $25 \mathrm{~mm}$ wide (tangential direction) were cut from these scantlings in accordance with the standard D 143-94 (ASTM 2007). The specimens were visually free from defects. The specimens came from random radial and longitudinal positions within the tree, but from the first two meters of tree height. The specimens were conditioned in a room set for $20^{\circ} \mathrm{C}$ and 
$75 \%$ relative humidity until reaching the equilibrium moisture content (EMC) of 14\% (during circa two weeks). They were then submitted to dynamic and static tests at this moisture content of $14 \%$.

\section{Experimental strategy}

328 specimens were cut from 103 scantlings: thus at least two wood specimens were cut from each beam. These two samples from the same scantling were considered as twin, as they came from the same beam and the longitudinal variability between $\sim 50 \mathrm{~mm}$ was considered null. Firstly, all wood samples were submitted to flexural vibration tests to estimate their dynamic elastic modulus. Then, 138 wood specimens were tested by three-point bending tests and 190 samples were submitted to four-point bending tests. A different number of specimens was used for the bending tests because, in some cases, it was not possible to extract four specimens (two for each bending test) from the same scantling. The descriptive analysis, linear regressions and the bivariate correlations were performed using SPSS statistics software (SPSS Inc., version 17,0 Chicago, IL).

\section{Dynamic tests on specimens}

The dynamic tests used to evaluate the elastic properties of the wood samples were based on acoustic resonance (Brancheriau and Baillères 2002a) and were previously described in Hein et al. (2012). The specimens were placed on elastic supports so as to generate free vibrations. An exciting impulse was produced by lightly striking the specimen with an hammer at the opposite side of the output transducer (acoustic microphone). The specimens were submitted to flexural (transverse) and longitudinal vibration tests. The flexural vibration was induced by an edgewise impact while the longitudinal vibration by an impact along the edge. The output signals were transmitted via a lowpass filter to an acquisition card on a computer and recorded. In transversal vibration, the first four vibration modes were measured and used for estimating the dynamic flexural modulus of elasticity $\left(\mathrm{E}_{\mathrm{F}}\right)$ of wood. In longitudinal vibrations, only the first vibration mode was measured and used for estimating the dynamic compression modulus of elasticity $\left(\mathrm{E}_{\mathrm{C}}\right)$. The analysis of the spectral signal, the selection of the peaks of the natural frequency of vibration of the wood samples and the estimates of the dynamic moduli were performed using the software BING ${ }^{\circledR}$ (CIRAD, Montpellier, France, version 9.1.3). The mass and dimension were measured and the density $(\rho)$ of each specimen was calculated. The instrument resolution was $0,01 \mathrm{~g}$ and $0,01 \mathrm{~mm}$ for mass and dimension, respectively. The maximum errors for dynamic E, obtained by means of this system, were lower than $5 \%$.

\section{Static tests}

The modulus of rupture (MOR) of the wood specimens was determined using an electromechanical universal testing machine (Adamel Lhomargy, model DY 36) of $100 \mathrm{kN}$ capacity in tractioncompression. Two types of static test were performed: 3-point and 4-point bending test with a span to depth ratio of 12,8 (Figure 1).

For the 3-point bending test, the span between lower supports was $320 \mathrm{~mm}$. The central loading point was fixed. The roller bearing diameter was $30 \mathrm{~mm}$. The test was conducted at a rate of $0,08 \mathrm{~mm} / \mathrm{s}$. The proportional limit, ultimate load, and deflection were obtained from load-deflection curves; and the MOR was calculated as follows (Equation 1).

$$
\mathrm{MOR}_{3 p}=\frac{3 \times F_{3} \times L}{2 \times e \times h^{2}}
$$

where $F_{3}$ is the load (force) at the fracture point $(\mathrm{N}), L$ is the length of the support span (m), $e$ is the width $(\mathrm{m})$ and $h$ is the thickness $(\mathrm{m})$ of the wood specimen.

Concerning the 4-point bending test, the span between lower supports was $320 \mathrm{~mm}$. The distance between the two loading points was $160 \mathrm{~mm}$ ( 1 free and 1 fixed). The roller bearing diameter was $60 \mathrm{~mm}$. The influence of loading point on the 3-point bending test was investigated by Yoshihara and Fukuda (1998). It was notably observed via the experimental figures that the effect of the radius of loading nose was small when the specimen had a low depth/span ratio. We deduced that 
this effect can be neglected for radii between $15 \mathrm{~mm}$ and $30 \mathrm{~mm}$ for a depth/span ratio of 1/12,8. The test was conducted at a rate of $0,08 \mathrm{~mm} / \mathrm{s}$. The MOR was calculated as follows (Equation 2).

$$
\operatorname{MOR}_{4 p}=\frac{3 \times F_{4} \times(L-a)}{2 \times e \times h^{2}}
$$

where $F_{4}$ is the load (force) at the fracture point $(\mathrm{N}), L$ is the length of the support span (m), $a$ is the distance between the 2 loading points (m), $e$ is the width and $h$ is the thickness $(\mathrm{m})$ of the wood specimen.

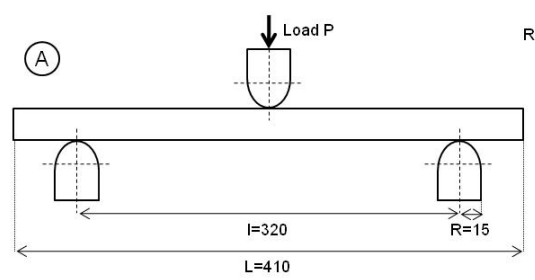

Ribs in mm


Figure 1. Scheme for three-point (A) and four-point (B) statistic bending tests in Eucalyptus wood. Dimensions are presented in $\mathrm{mm}$.

\section{RESULTS}

\section{Sampling variability}

Table 1 lists the statistical summary of density, dynamic tests (modulus of elasticity) and static test results (modulus of rupture). The set of 328 wood specimens of Eucalyptus investigated in this study presented a wide range of values for elastic and rupture modulus $(\mathrm{CV}=\sim 20 \%)$ with air-dried density $(\rho)$ values ranging from $\sim 360$ to $710 \mathrm{~kg} \cdot \mathrm{m}^{-3}$. The longitudinal vibration test resulted in significantly higher ( $t$ value: 2,17 ; df: 327; Sig: 0,03$)$ mean value (13386 MPa) than that from flexural $(12496 \mathrm{MPa})$ tests. The wood strength obtained from the 3 -point bending test $\left(\mathrm{MOR}_{3 \mathrm{p}}=76,8 \mathrm{MPa}\right)$ was significantly higher ( $t$ value: 23,33 ; df: 137; Sig: 0,00$)$ than that from the 4-point bending test $\left(\mathrm{MOR}_{4 \mathrm{p}}=73,0 \mathrm{MPa}\right)$. 
Table 1. Descriptive statistics for density $\left(\rho, \mathrm{kg} \times \mathrm{m}^{-3}\right)$, dynamic elastic modulus in longitudinal $\left(\mathrm{E}_{\mathrm{L}}\right.$, $\mathrm{MPa})$ and flexural $\left(\mathrm{E}_{\mathrm{F}}, \mathrm{MPa}\right)$ vibrations, and modulus of rupture obtained by three- $\left(\mathrm{MOR}_{3 \mathrm{p}}, \mathrm{MPa}\right)$ and four-point $\left(\mathrm{MOR}_{4 \mathrm{p}}, \mathrm{MPa}\right)$ bending tests.

\begin{tabular}{ccccccc}
\hline Trait & Average & sd & Min & Max & CV & N \\
\hline$\rho$ & 517,7 & 59,84 & 362,5 & 708,4 & 11,6 & 328 \\
\hline $\mathrm{E}_{\mathrm{L}}$ & 13,386 & $2,566,3$ & 6,522 & 20,785 & 19,2 & 328 \\
\hline $\mathrm{E}_{\mathrm{F}}$ & 12,496 & $2,366,2$ & 5,930 & 18,732 & 18,9 & 328 \\
\hline $\mathrm{MOR}_{3 \mathrm{p}}$ & 76,8 & 15,8 & 31,0 & 122,0 & 20,5 & 138 \\
\hline $\mathrm{MOR}_{4 \mathrm{p}}$ & 73,0 & 15,5 & 25,0 & 119,0 & 21,3 & 190 \\
\hline
\end{tabular}

\section{Correlation among wood traits}

Correlation among wood density and the mechanical characteristics obtained from dynamic and static tests are presented in Table 2. In addition, scatter-plots between moduli of rupture and moduli of elasticity, between moduli of rupture and wood density, and between moduli of rupture are presented in Figure 2, Figure 3 and Figure 4. The correlations between physico-mechanical properties were statistically significant $(\rho<0,001)$ and above 0,68 . More specifically, the link between $\mathrm{MOR}_{3 p}$ and $\mathrm{MOR}_{4 \mathrm{p}}$ was found to have the highest correlation value within Table 2. Considering the entire range in Figure 4, lower and higher MOR values obtained from four-points appear to be underestimated when compared to MOR 3 values. Riyanto and Gupta (1998) have reported no correlation between E and shear strength obtained in 3-point and 4-point bending tests in Pseudotsuga menziesii wood. Wood density had higher correlation with $\mathrm{MOR}_{3 \mathrm{p}}(0,76)$ than those with $\mathrm{MOR}_{4 \mathrm{p}}(0,68)$ (Figure 3). On the other hand, the correlations between $\mathrm{E}_{\mathrm{L}}$ or $\mathrm{E}_{\mathrm{F}}$ with $\mathrm{MOR}$ presented similar values (circa 0,76 for $\mathrm{MOR}_{3 \mathrm{p}}$ and 0,80 for $\mathrm{MOR}_{4 \mathrm{p}}$, Table 2 and Figure 2). Using either EL or EF as independent variable, MOR4p presented higher correlations and lower SEE values than $\mathrm{MOR}_{3 \mathrm{p}}$. This finding indicates that 4-point bending tests are more sensitive to wood stiffness variations than the 3-point bending tests. The correlation value was found to be identical $(0,76)$ between MOR $_{3 p}$ and density or elastic moduli (Table 2). Ilic (2001) has compared the dynamic properties with static modulus and the modulus of rupture obtained from a threepoint bending test using Eucalyptus delegatensis samples. He has reported correlation between MOR and $\mathrm{E}_{\mathrm{F}}$ of 0,90 and between MOR and density of 0,77. Igartúa et al. (2015) studied the relationship between the density and the mechanical properties of Acacia melanoxylon reporting coefficients of determination $\left(\mathrm{R}^{2}\right)$ ranging from 0,73 to 0,87 between density and mechanical properties. They present a $\mathrm{R}^{2}$ of 0,72 between modulus of elasticity and bending strength obtained in 3-point bending tests.

In short, the correlation between strength and stiffness was higher for the four-point bending test (Figure 2), whereas the correlation between MOR and wood density was higher for three-point bending test (Figure 3). A good relationship is observed between the flexural wood strength obtained by threepoint and four-point bending tests (Figure 4). 
Table 2. Correlation among density $\left(\rho, \mathrm{kg} \mathrm{m}^{-3}\right)$, dynamic elastic modulus in longitudinal $\left(\mathrm{E}_{\mathrm{L}}, \mathrm{MPa}\right)$ and flexural $\left(\mathrm{E}_{\mathrm{F}} \mathrm{MPa}\right)$ vibrations, and modulus of rupture obtained by three- point $\left(\mathrm{MOR}_{3 \mathrm{p}}, \mathrm{MPa}\right)$ and fourpoint $\left(\mathrm{MOR}_{4 \mathrm{p}}, \mathrm{MPa}\right)$ bending tests. All correlations were statistically significant at $\rho<0,001$.

\begin{tabular}{|c|c|c|c|c|}
\hline & $\rho$ & $\mathrm{E}_{\mathrm{L}}$ & $\mathrm{E}_{\mathrm{F}}$ & $\mathrm{MOR}_{3 \mathrm{p}}$ \\
\hline $\mathrm{E}_{\mathrm{L}}$ & 0,80 & & & \\
\hline $\mathrm{E}_{\mathrm{F}}$ & 0,77 & 0,97 & & \\
\hline $\mathrm{MOR}_{3 \mathrm{p}}$ & 0,76 & 0,76 & 0,75 & \\
\hline $\mathrm{MOR}_{4 \mathrm{p}}$ & 0,68 & 0,79 & 0,81 & 0,86 \\
\hline
\end{tabular}

\section{DISCUSSION}

\section{Influence of testing method on wood stiffness and strength}

The mean $\mathrm{MOR}_{3 \mathrm{p}}$ value $(76,8 \mathrm{MPa})$ was significantly higher than the $\mathrm{MOR}_{4 \mathrm{p}}$ value $(73,0 \mathrm{MPa})$ (Table 1). This difference of mean values between testing methods can be explained by the location of the maximum bending moment and maximum axial fiber stress. The maximum stress occurs directly below the loading head in the three-point test but is spread out over the area between the two loading heads in the four-point system (Chitchumnong et al. 1989). Thus, the 4-point bending test produces maximum stress along an extended region of the wood specimen, exposing a longer beam length to the influence of internal stress in the rupture. For instance, Chitchumnong et al. (1989) have investigated flexural strength in denture-base polymers finding flexural strength values statistically higher in three-point bending than in four-point bending. The test conditions, both in three-point or four-point bending, allow specimens to bend in large deformations before the rupture happens, which is very far from the hypothesis of the elastic bending theory (which notably supposed small displacements and linear stress distribution through the depth of the beam) (Chitchumnong et al. 1989).


Figure 2. Linear regression plot between the dynamic flexural (A) or longitudinal (B) elastic modulus and the MOR obtained by three- and four-point bending tests of Eucalyptus wood. SEE is the standard error of estimation. 
The mean values of dynamic modulus of elasticity (Table 1) were found to be higher in longitudinal vibration (13386 MPa) than in flexural vibration (12496 MPa). In flexural vibration, the Bernoulli or the Timoshenko theoretical models can be applied (Brancheriau 2002a). The Bernoulli's hypotheses consider the beam as a thin line neglecting the shearing deformation and the rotary inertia of the cross section. The exact solution to the model of Timoshenko was proposed by Brancheriau (2014) and this model was used because it gives a better estimation of the modulus of elasticity value. Haines et al. (1996) have studied the relationships between moduli of elasticity obtained by the 4 point bending test, longitudinal vibration test, flexural vibration test (Bernoulli) and ultrasonic test in transmission (time of flight). The mean value of modulus from the longitudinal vibration test was higher than the mean value obtained from the flexural vibration test ( $6 \%$ and $11 \%$ for spruce and fir, respectively). The mean value of moduli from the ultrasonic test exceeds the mean value obtained from the flexural vibration test ( $17 \%$ and $22 \%$ for spruce and fir, respectively). These variations were attributed to the viscoelasticity and to the non-homogeneity of wood (Haines 1996). The equations allowing the determination of the modulus of elasticity in dynamic or static tests assumed homogeneous and elastic materials. Wood is nonhomogeneous due primarily to its particular anatomy and to the presence of early and late wood. Wood is also known as a viscoelastic material and the modulus of elasticity computed assuming a strict elastic behavior is frequency dependent (ultrasonic tests use higher frequencies than flexural vibration tests).

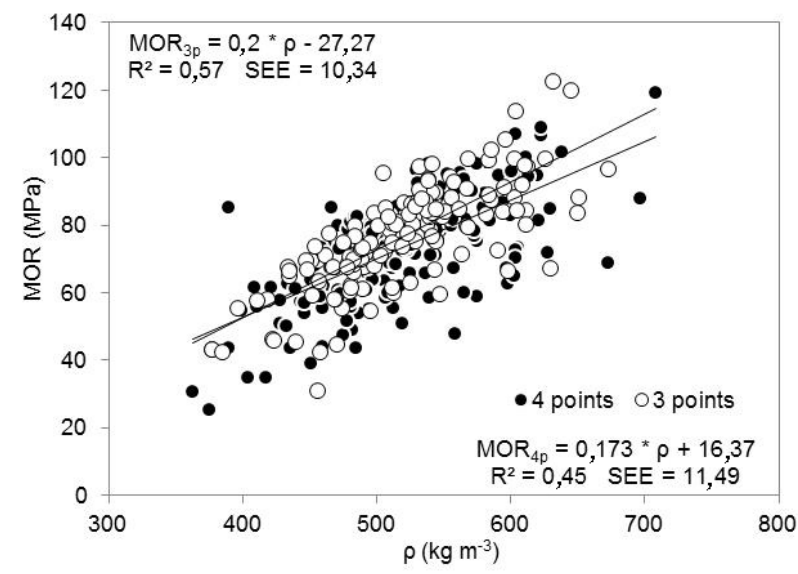

Figure 3. Linear regression plot between the wood density and the MOR obtained by three and fourpoints bending tests of Eucalyptus wood. SEE is the standard error of estimation.

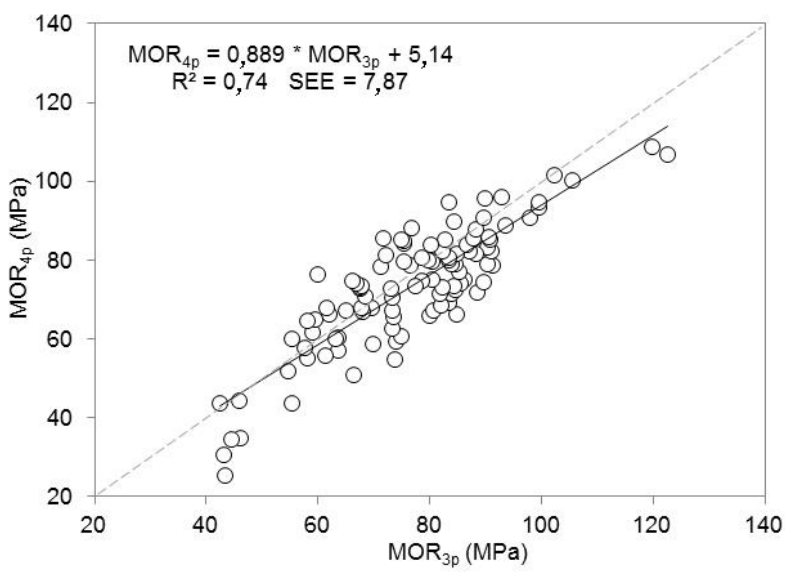

Figure 4. Linear regression plot between the MOR obtained by three and four-point bending tests of Eucalyptus wood. SEE is the standard error of estimation. 


\section{Predicting wood strength by nondestructive properties}

Wood is a cellular solid and its macroscopic physico-mechanical properties depend on the arrangement of the cells and of course, on the properties of the cells (Gibson and Ashby 1997). This explains why the macroscopic density, modulus of elasticity and modulus of rupture are interconnected. A four-point bending test is more in agreement with the hypothesis of the beam theory (Saint-Venant's hypothesis states that the results obtained are valid only at a distance sufficiently far from the region of application of the intense forces) which leads to an estimation of the modulus of elasticity and modulus of rupture closed to the "true" values (Brancheriau et al. 2002b). Thus, density, modulus of elasticity and rupture should be strongly linked if a four-point bending test is considered. However, the experimental observations did not verify this last assertion. The correlation with density was higher for a modulus of rupture determined in three-point bending $\left(0,76\right.$ for $\mathrm{MOR}_{3 \mathrm{p}}$ and 0,68 for $\mathrm{MOR}_{4 \mathrm{p}}$, Table 2). This linear regression plot shows that density seems to be the best predictor for modulus of rupture calculated from a 3-point bending test. The correlations between elastic moduli and moduli of rupture were similar (circa 0,76 for $\mathrm{MOR}_{3 \mathrm{p}}$ and 0,80 for $\mathrm{MOR}_{4 \mathrm{p}}$, Table 2). The same observation was done considering the link between the modulus of rupture in 3 point bending and the non-destructive properties (similar correlation of 0,76 Table 2). This phenomenon was explained by the fact that the modulus of rupture defined in Equation 2 is not the true maximum stress. This equation is based on the hypothesis that the stresses are distributed linearly and symmetrically in the cross section of a bent beam. For wood, this hypothesis is valid only up to the elastic limit in compression. The difference between the tensile strength and the compression strength explains the particular behavior of a wood beam in bending (Kollmann and Côté 1968). During a bending test, and after the elastic limit in compression, the neutral axis "moves" toward the tense part. The rupture first occurs in the compressed part of the beam. Finally the breakage occurs in tension. Figure 5 illustrates the stress distribution in a bent wood.

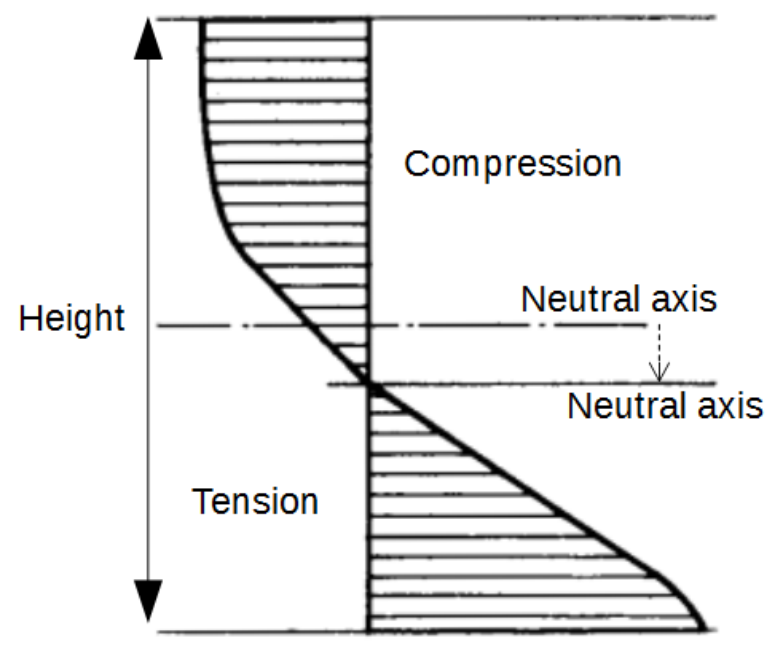

Figure 5. Schematic stress distribution in a bent wood beam at the ultimate stress in compression and after the elastic limit in tension.

\section{CONCLUSIONS}

The bending strength determined as MOR is the most used characteristics of wood resistance. The key results of this study showed that the wood resistance values and their relationship with stiffness and density vary according to the characterization method (either 3- or 4- point bending tests). MOR obtained from 3-point bending tests was found to be 5,2\% higher than that from 4-point bending test in Eucalyptus wood specimens from fast grown plantations. This was particularly true for the low MOR values in 4-point when compared to 3-point values. The volume of wood under maximum stress is higher in the case of a 4-point bending test, exposing a longer beam length to the influence of internal 
cracks or flaws in the rupture. The correlation of MOR in 3-point bending with density was higher $\left(\mathrm{R}^{2}=0,57\right)$ than in 4-point bending $\left(\mathrm{R}^{2}=0,45\right)$ while the correlations between dynamic elastic moduli and MOR were similar (circa $\mathrm{R}^{2}=0,57$ in 3-point and $\mathrm{R}^{2}=0,65$ in 4-point). A 4-point bending test is more in agreement with the Saint-Venant's hypothesis. However, the MOR values as computed in 3- or 4-point tests is not the true maximum stress in bending but must be considered as conventional values.

\section{ACKNOWLEDGMENTS}

The author expresses your special thanks to the CENIBRA NIPO-BRASILEIRA for providing trees; to the Wood Science and Technology Laboratory of the Universidade Federal de Lavras (UFLA, Brazil) for supporting the experimental work and to the Centre de Cooperation Internationale en Recherche Agronomique pour le Development (UPR114 of CIRAD, Montpellier, France) for laboratory facilities. This study was funded by CENIBRA (Celulose Nipo-Brasileira), CIRAD (Unit 114, BioWooEB), CNPq (Conselho Nacional de Desenvolvimento Científico e Tecnológico, Brazil, process no. 405085/2016-8), and FAPEMIG (Fundação de Amparo à Pesquisa do Estado de Minas Gerais, Brazil, process APQ-00509-14). P.R.G. Hein was supported by CNPq (process no. 303675/2017-9) grants.

\section{REFERENCES}

ASTM. 2007. American Society for Testing and Materials. D 143-94 - Standard test methods for small, clear specimens of timber. 32 p. West Conshohocken, PA, USA.

Brancheriau, L.; Baillères, H. 2002a. Natural vibration analysis of clear wooden beams: a theoretical review. Wood Science and Technology 36:347-365.

Brancheriau, L.; Baillères, H.; Guitard, D. 2002b. Comparison between modulus of elasticity values calculated using 3 and 4 point bending tests on wooden samples. Wood Science and Technology 36:367-383.

Brancheriau, L. 2014. An alternative solution for the determination of elastic parameters in freefree flexural vibration of a Timoshenko beam. Wood Science and Technology 48 (6):1269-1279.

Chitchumnong, P.; Brooks, S.C.; Stafford, G.D. 1989. Comparison of three- and four-point flexural strength testing of denture-base polymers. Dental Materials 5:2-5.

Gibson, L.J.; Ashby, M.F. 1997. Cellular solids. Cambridge University Press. Second edition. p. $387-428$.

Gustafsson, S. I. 2001. Mechanical Properties of some Swedish hard wood species. Proceedings of the Institution of Mechanical Engineers 215:125-131.

Haines, D.W.; Leban, J.M.; Herbe, C. 1996. Determination of Young's modulus for spruce, fir and isotropic materials by the resonance flexure method with comparisons to static flexure and other dynamic methods. Wood Science and Technology 30:253-263.

Hein, P.R.G.; Lima, J.T.; Gril, J.; Rosado, A.M.; Brancheriau, L. 2012. Resonance of structural timbers indicates the stiffness even of small specimens of Eucalyptus from plantations. Wood Science and Technology 46 (4):621-635.

Igartúa, D.V; Moreno, K.; Piter, J.C.; Monteoliva, S. 2015. Densidad y propiedades mecánicas de la madera de Acacia melanoxylon implantada en Argentina. Maderas-Cienc Tecnol 17(4): 809-820.

Ilic, J. 2001. Relationship among the dynamic and static elastic properties of air-dry Eucalyptus 
delegatensis R. Baker. Holz als Roh- und Werkstoff 59:169-175.

Kollmann, F.F.P.; Côté, W.A. 1968. Principles of wood science and technology. Solid wood. Springer-Verlag. p. 359-363.

Kumar, M.P.; Murthy, V.B. 2012. Effect of Specimen Dimensions on Flexural Modulus in a 3-Point Bending Test. International Journal of Engineering Research \& Technology 1 (8):1-6.

Hayat, M.A.; Suliman, S.M.A. 1998. Mechanical and structural properties of glass reinforced phenolic laminates. Polymer Testing 17:79-97.

Mujika, F. 2006. On the difference between flexural moduli obtained by three-point and four-point bending tests. Polymer Testing 25:214-220.

Naylor, A.; Hackney, P.; Perera, N. 2012. Determination of wood strength properties through standard test procedures. Proceedings of the $10^{\text {th }}$ International Conference on Manufacturing Research 372-377.

Riyanto, D.; Gupta, R. 1998. A comparison of test methods for evaluating shear strength of structural lumber. Forest Products Journal 48 (2):83-90.

Sales, C. 1977. The rheological study of tropical woods: Modulus of elasticity. Bois et Forêts des Tropiques 176:47-65.

Yoshihara, H.; Fukuda, A. 1998. Influence of loading point on the static bending test of wood. Journal of Wood Science 44 (6):473-481.

Yoshihara, H.; Kubojima, Y.; Ishimoto, T. 2003. Several examinations on the static bending test methods of wood using todomatsu (Japanese fir). Forest Products Journal 53: 39-44. 